\title{
Outcome of total elbow replacement for distal humeral fractures in the elderly
}

\author{
A COMPARISON OF PRIMARY SURGERY AND SURGERY AFTER \\ FAILED INTERNAL FIXATION OR CONSERVATIVE TREATMENT
}

N. Prasad,
C. Dent

From the University

Hospital of Wales, Cardiff, Wales
N. Prasad, MRCSEd, MS, DNB, Registrar in Trauma \& Orthopaedics

Morriston Hospital, Heol Maes Eglwys, Morriston, Swansea SA6 6NL, UK.

C. Dent, FCCS, FRCS(Trauma \& Orth), MS, Professor

Llandough Hospital,

Llandough,

Cardiff CF64 2XX, UK.

Correspondence should be sent to $\mathrm{Mr}$ N. Prasad at 5 Lovage Close, Pontprennau, Cardiff CF23 8SB, UK; e-mail: nporth@yahoo.com

(C)2008 British Editorial Society of Bone and Joint Surgery doi:10.1302/0301-620X.90B3 $18971 \$ 2.00$

Bone Joint Surg $[\mathrm{Br}]$ 2008;90-B:343-8.

Received 29 November 2006; Accepted after revision 2

October 2007

\begin{abstract}
We analysed the outcome of the Coonrad-Morrey total elbow replacement used for fracture of the distal humerus in elderly patients with no evidence of inflammatory arthritis and compared the results for early versus delayed treatment. We studied a total of 32 patients with 15 in the early treatment group and 17 in the delayed treatment group. The mean follow-up was 56.1 months (18 to 88). The percentage of excellent to good results based on the Mayo elbow performance score was not significantly different, $84 \%$ in the early group and $79 \%$ in the delayed group. Subjective satisfaction was $92 \%$ in both the groups.

One patient in the early group developed chronic regional pain syndrome and another type 4 aseptic loosening. Two elbows in the early group also showed type 1 radiological loosening.

Two patients in the delayed group had an infection, two an ulnar nerve palsy, one developed heterotopic ossification and one type 4 aseptic loosening. Two elbows in this group also showed type 1 radiological loosening. The Kaplan-Meier survivorship analysis for the early and delayed treatment groups was $93 \%$ at 88 months and $76 \%$ at 84 months, respectively.

No significant difference was found between the two groups.
\end{abstract}

Comminuted fractures of the distal humerus are best managed surgically by anatomical reduction and rigid internal fixation. This is often not possible in elderly patients because of the osteoporotic nature of the bone and increased comminution of the fracture.

Total elbow replacement (TER) has evolved as an acceptable treatment with encouraging results both for acute distal humeral fractures in the elderly, ${ }^{1-5}$ and distal humeral nonunion. ${ }^{6,7}$ Many of the reported studies have included patients with associated inflammatory arthropathy. ${ }^{1,4}$ The medium and long-term results after TER in patients with rheumatoid arthritis (RA) have been shown to be good but this may be partly because of low functional demands. ${ }^{8,9}$

The aim of our study was to analyse the longterm results of TER for the treatment of fractures of the distal humerus in elderly patients with no evidence of inflammatory arthropathy. We wished to compare the results in patients who underwent a TER for acute fractures with those who underwent a TER after failed primary treatment.

\section{Patients and Methods}

We retrospectively reviewed the records of 164 patients who were treated with TER. We iden- tified a series of 38 patients treated by TER between 1997 and 2003 for fractures of the distal humerus. We excluded four patients with associated inflammatory arthritis of the elbow and two who had TER for post-traumatic arthritis. A total of 32 patients were thus included in the final study. There were five patients who had died from causes unrelated to the TER. The data obtained from the case notes of these patients were used for analysis of the final range of movement of the elbow and for survivorship analysis. The remaining 27 patients were assessed using the Mayo elbow performance score. ${ }^{10}$ All patients, except one who was involved in a motorcycle accident, had sustained a low-energy injury because of a fall. All were closed injuries.

Of these patients, 15 had been referred with acute fractures of the distal humerus which were deemed unsuitable for fixation by the surgical team in their primary care hospital due to the configuration of the fracture and the osteoporotic nature of the bone. The mean age of these patients was 78 years (61 to 89). All fractures were multifragmentary intra-articular $\mathrm{AO}^{11}$ type $\mathrm{A} 3, \mathrm{~B} 3$ or $\mathrm{C} 3$. There were 11 women and four men (Table I). The delay between injury and surgery, a mean of two 
Table I. Acute group treated by total elbow replacement $(n=15)$

\begin{tabular}{|c|c|c|c|c|c|c|c|c|}
\hline Gender & $\begin{array}{l}\text { Age at } \\
\text { operation (yrs) }\end{array}$ & $\begin{array}{l}\text { Time to surgery } \\
\text { (wks) }\end{array}$ & $\begin{array}{l}\text { Type of fracture } \\
\text { (AO) }\end{array}$ & $\begin{array}{l}\text { Follow-up } \\
\text { (mths) }\end{array}$ & Arc of flexion( $\left(^{\circ}\right)$ & Pain $^{*}$ & $\begin{array}{l}\text { MEPS }^{\dagger} \text { at final } \\
\text { follow-up }\end{array}$ & Complications \\
\hline $\mathrm{F}$ & 68 & 4 & B3 & 88 & 0 to 140 & 30 & 85 & $\begin{array}{l}\text { Type } 1 \text { radiological } \\
\text { loosening }\end{array}$ \\
\hline $\mathrm{F}$ & 88 & 2 & $\mathrm{C} 3$ & 32 & 30 to 100 & 30 & 75 & \\
\hline $\mathrm{F}$ & 75 & 2 & $\mathrm{C} 3$ & 60 & 70 to 120 & 45 & 85 & \\
\hline $\mathrm{F}$ & 89 & 1 & $\mathrm{C} 3$ & 42 & 15 to 90 & 15 & 60 & $\begin{array}{l}\text { Pre-operative ulnar nerve } \\
\text { injury leading to chronic } \\
\text { regional pain syndrome }\end{array}$ \\
\hline $\mathrm{F}$ & 73 & 3 & $\mathrm{~A} 3$ & 72 & 10 to 140 & 45 & 100 & \\
\hline M & 81 & 1 & $\mathrm{C} 3$ & 72 & 30 to 110 & 30 & 80 & \\
\hline $\mathrm{F}$ & 77 & 3 & $\mathrm{C} 3$ & 76 & 30 to 90 & 45 & 90 & \\
\hline $\mathrm{F}$ & 86 & 1 & $\mathrm{C} 3$ & 48 & 20 to 130 & 45 & 95 & \\
\hline M & 80 & 1 & $\mathrm{C} 3$ & 48 & 30 to 110 & 45 & 85 & \\
\hline M & 61 & 3 & B3 & $\begin{array}{l}24 \text { (at the } \\
\text { time of } \\
\text { revision) }\end{array}$ & 30 to 110 & $\begin{array}{l}\text { Moderate pain } \\
\text { before revision }\end{array}$ & $\begin{array}{l}60 \text { (at final } \\
\text { follow up) }\end{array}$ & $\begin{array}{l}\text { Revision for aseptic } \\
\text { loosening of ulna }\end{array}$ \\
\hline $\mathrm{F}$ & 77 & 3 & $\mathrm{C} 3$ & 58 & 25 to 120 & 45 & 90 & \\
\hline $\mathrm{F}$ & 81 & 4 & $\mathrm{C} 3$ & 64 & 30 to 130 & 45 & 95 & \\
\hline M & 79 & 1 & A3 & 36 & 20 to 130 & 30 & 80 & $\begin{array}{l}\text { Type } 1 \text { radiological } \\
\text { loosening }\end{array}$ \\
\hline $\mathrm{F}^{\neq}$ & 83 & 2 & B3 & 38 & 20 to 120 & Mild pain & & \\
\hline $\mathrm{F}^{\ddagger}$ & 76 & 2 & B3 & 28 & 30 to 140 & No pain & & \\
\hline
\end{tabular}

* according to Mayo elbow performance score ${ }^{10}$

† MEPS, Mayo elbow performance score ${ }^{10}$

$\ddagger$ patient died from unrelated causes

Table II. Patients treated by total elbow replacement after a delayed period $(n=17)$

\begin{tabular}{|c|c|c|c|c|c|c|c|c|c|}
\hline Gender & $\begin{array}{l}\text { Age at oper- } \\
\text { ation (yrs) }\end{array}$ & $\begin{array}{l}\text {-Time to surgery } \\
\text { (wks) }\end{array}$ & $\begin{array}{l}\text { Type of fracture } \\
\text { (AO) }\end{array}$ & $\begin{array}{l}\text { Primary } \\
\text { procedure }\end{array}$ & $\begin{array}{l}\text { Follow-up } \\
\text { (mths) }\end{array}$ & Arc of flexion $\left({ }^{\circ}\right)$ & Pain ${ }^{*}$ & $\begin{array}{l}\text { MEPS }{ }^{\dagger} \text { At final } \\
\text { follow-up }\end{array}$ & Complications \\
\hline $\mathrm{F}$ & 79 & 72 & A3 & \multicolumn{2}{|c|}{ Conservative 64} & 20 to 130 & 45 & 100 & \\
\hline $\mathrm{F}$ & 65 & 32 & A3 & K-wire & 81 & 70 to 120 & 30 & 80 & $\begin{array}{l}\text { Heterotopic ossifica- } \\
\text { tion. Type } 1 \text { radiologi- } \\
\text { cal loosening }\end{array}$ \\
\hline $\mathrm{F}$ & 66 & 96 & $\mathrm{~A} 3$ & K-wire & 78 & 40 to 140 & 45 & 95 & $\begin{array}{l}\text { Type } 1 \text { radiological } \\
\text { loosening }\end{array}$ \\
\hline M & 67 & 80 & \multicolumn{2}{|c|}{$\begin{array}{l}\mathrm{B} 3 \text { + radial head K-wire } \\
\text { fracture }\end{array}$} & 66 & 50 to 120 & 30 & 75 & \\
\hline M & 65 & 96 & \multicolumn{2}{|c|}{$\begin{array}{l}\mathrm{B} 3 \text { + radial head K-wire } \\
\text { fracture }\end{array}$} & 42 & 0 to 130 & 45 & 100 & \\
\hline $\mathrm{F}$ & 81 & 32 & A3 & $\begin{array}{l}\text { ORIF }^{\ddagger} \\
\text { bone graft }\end{array}$ & 45 & 0 to 100 & 45 & 95 & \\
\hline $\mathrm{F}$ & 65 & 96 & B3 & ORIF & 84 & 15 to 110 & 45 & 100 & $\begin{array}{l}\text { Type } 1 \text { radiological } \\
\text { loosening }\end{array}$ \\
\hline $\mathrm{F}$ & 66 & 28 & \multicolumn{2}{|c|}{$\begin{array}{l}\mathrm{B} 3 \text { + radial head ORIF } \\
\text { fracture }\end{array}$} & \multicolumn{2}{|c|}{72 (at revision)70 to 120} & 15 & $\begin{array}{l}60 \text { (at final } \\
\text { follow-up) }\end{array}$ & $\begin{array}{l}\text { Loosening of both } \\
\text { radius and ulna - } \\
\text { revision }\end{array}$ \\
\hline $\mathrm{F}$ & 73 & 56 & $\mathrm{C} 3$ & \multicolumn{2}{|c|}{ Conservative 74} & 50 to 140 & 45 & 80 & \\
\hline $\mathrm{F}$ & 65 & 48 & B3 & K-wire & 70 & 20 to 130 & 30 & 70 & \\
\hline $\mathrm{F}$ & 61 & 96 & $\mathrm{C} 3$ & \multicolumn{2}{|c|}{$\begin{array}{l}\text { ORIF + radial } 79 \\
\text { head } \\
\text { excision }\end{array}$} & 0 to 130 & 30 & 80 & \\
\hline $\mathrm{F}$ & 68 & 48 & B3 & \multicolumn{2}{|c|}{ Conservative 41} & 40 to 120 & 30 & 75 & \\
\hline $\mathrm{F}$ & 86 & 3 & $\mathrm{~A} 3$ & K-wire & 40 & 20 to 130 & 45 & 90 & Ulnar nerve injury \\
\hline $\mathrm{F}$ & 81 & 1 & $\mathrm{C} 3$ & K-wire & \multicolumn{2}{|c|}{$\begin{array}{l}42 \text { (at the time } 35 \text { to } 95 \\
\text { of implant } \\
\text { removal) }\end{array}$} & 15 & $\begin{array}{l}55 \text { (at final } \\
\text { follow-up) }\end{array}$ & $\begin{array}{l}\text { Ulnar nerve injury, } \\
\text { early superficial and } \\
\text { late deep infection, } \\
\text { chronic regional pain } \\
\text { syndrome - implant } \\
\text { removal }\end{array}$ \\
\hline $\mathrm{F}^{\S}$ & 84 & 2 & $\mathrm{C} 3$ & \multicolumn{2}{|c|}{ Conservative 18} & 40 to 110 & No pain & & $\begin{array}{l}\text { Superficial wound } \\
\text { infection }\end{array}$ \\
\hline $\mathrm{F}^{\S}$ & 86 & 32 & $\mathrm{C} 3$ & ORIF & 40 & 35 to 120 & No pain & & \\
\hline$M^{\S}$ & 79 & 48 & $\mathrm{~A} 3$ & K-wire & 36 & 40 to 110 & Mild pain & & $\begin{array}{l}\text { Type } 1 \text { radiological } \\
\text { loosening }\end{array}$ \\
\hline
\end{tabular}

* according to Mayo elbow performance score ${ }^{10}$

† MEPS, Mayo elbow performance score ${ }^{10}$

‡ ORIF, open reduction and internal fixation

$\S$ patient died from unrelated causes 


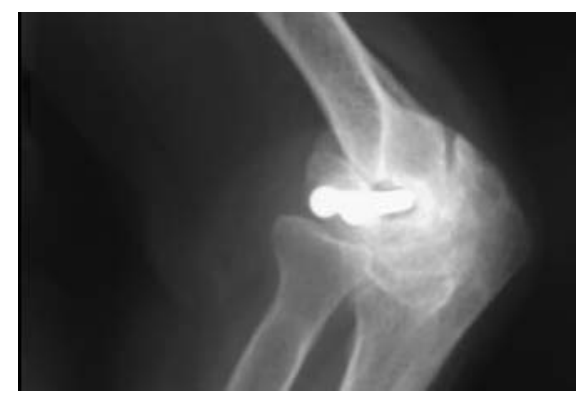

Fig. 1a

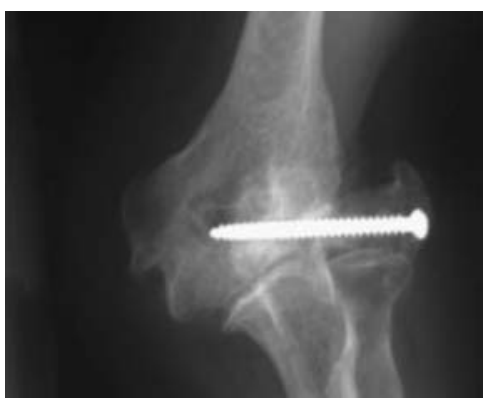

Fig. 1b

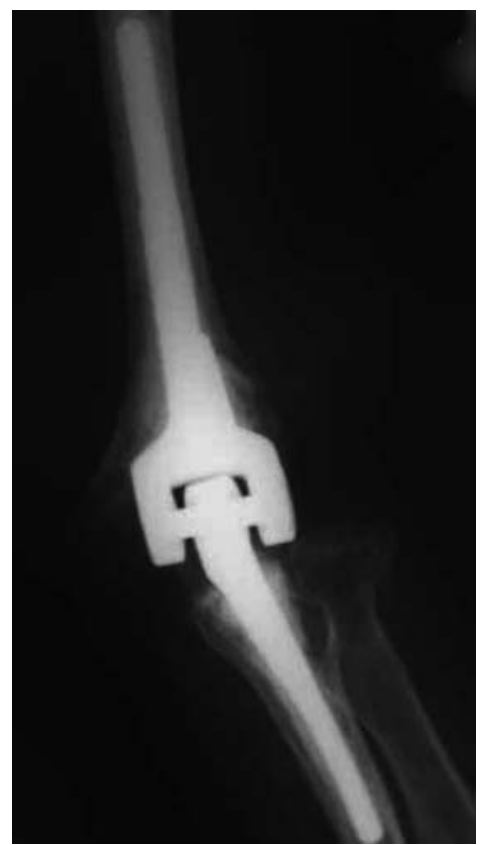

Fig. 1c

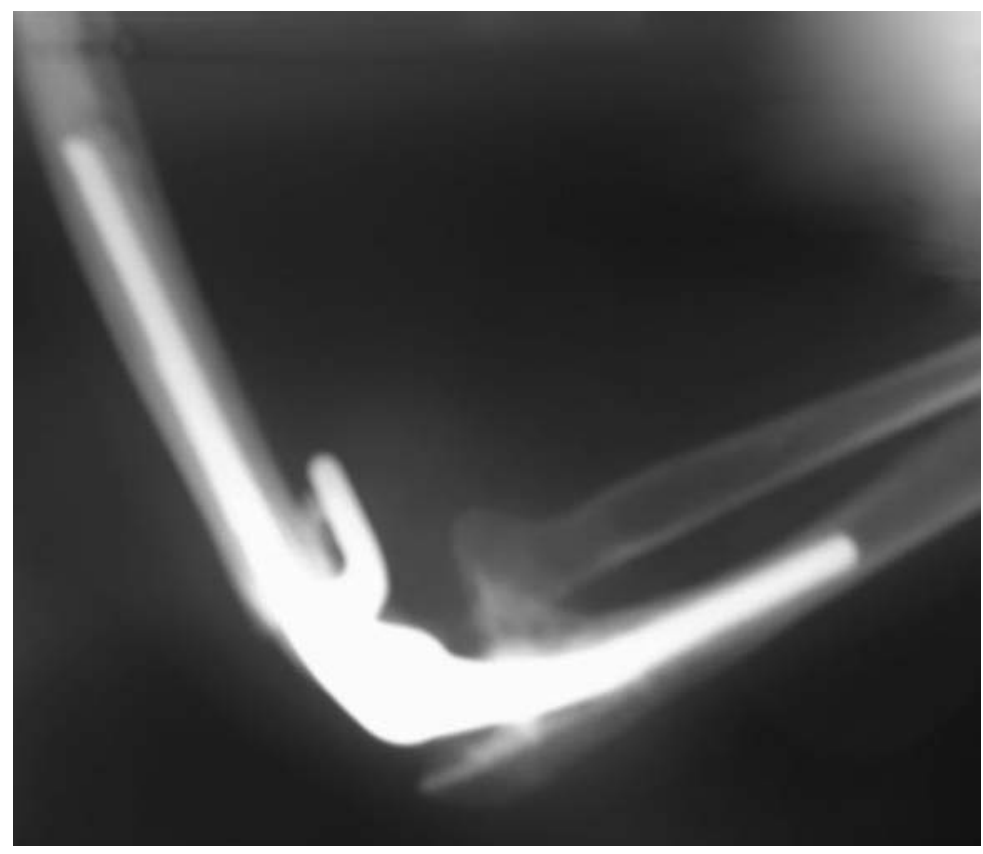

Fig. 1d

a) and b) Failed primary fixation of a fracture of the distal humerus leading to nonunion treated by c) and d) total elbow replacement.

weeks (1 to 4$)$, reflects thefact that our departmentis nonacute and inter-hospital transfer can be a limiting factor. It also reflects the age of the patients and the need for preoperative optimisation of comorbid conditions.

There were 17 patients who were referred with painful nonunion of a fracture of the distal humerus (Table II). Of these, 13 had undergone unsuccessful attempts at fixation (Fig. 1), and in one patient infection had occurred. The remaining four had been treated conservatively in plaster. The mean age of this delayed group was 73 years (61 to 86). There were 14 women and three men. There were six A3, six B3 and five C3 fractures. ${ }^{11}$ The mean time between injury and TER was 56 weeks (16 to 96).

Operative technique. The senior author (CD) performed all procedures. Surgery was performed using a combination of regional and general anaesthesia, and under tourniquet con- trol. Pre-operative intravenous antibiotics (1.5 mg cefuroxine) were used in all cases. A triceps turn-down approach is used. The ulnar nerve is identified, protected and mobilised to allow exposure. We did not have to translocate the ulnar nerve in any of the cases as it was neither unstable nor under tension after implantation of the prosthesis. After preparation of the humerus and ulna, including excision of distal humeral fragments, a soft-tissue assessment is made and any releases necessary are performed. An appropriately sized Coonrad-Morrey prosthesis (Zimmer, Warsaw, Indiana) is cemented into position. The radial head is not excised. Some patients had excision of the radial head performed by the referring orthopaedic surgeons during the initial attempted internal fixation. The triceps is repaired with an absorbable suture and the wound closed over a suction drain. Two further intravenous antibiotic doses 
Table III. Summary of results

\begin{tabular}{lccc}
\hline & Total group & Early TER ${ }^{*}$ group & Delayed TER group \\
\hline Number of patients & 32 & 15 & 17 \\
Mean (range) follow-up (mths) & $56.1(18$ to 88$)$ & 55.6 (28 to 88$)$ & $57(18$ to 84$)$ \\
Mean (range) flexion deformity $\left(^{\circ}\right)$ & $29 \quad(0$ to 70$)$ & $27 \quad(0$ to 70$)$ & $30(0$ to 70$)$ \\
Mean (range) maximum flexion $\left(^{\circ}\right)$ & $120 \quad(90$ to 140$)$ & 120 (90 to 140$)$ & $120(95$ to 140$)$ \\
Median (range) MEPS & $85 \quad(55$ to 100$)$ & $85(60$ to 100$)$ & $80(55$ to 100$)$ \\
Number of excellent to good results based on MEPS & 22 of 27 alive & 11 of 13 alive & 11 of 14 alive \\
Survivorship (Kaplan-Meier) & $84 \%$ at 88 months & $93 \%$ at 88 months & $76 \%$ at 84 months \\
\hline
\end{tabular}

* TER, total elbow replacement

† MEPS, Mayo elbow performance score ${ }^{10}$

Table IV. Comparison of Mayo elbow performance score ${ }^{10}$ (MEPS) and Mayo radiological staging

\begin{tabular}{lllllll}
\hline & MEPS & Pain & ROM $^{*}$ & Stability & $\mathbf{A D L}^{\dagger}$ & Radiolucency \\
\hline Early & 84.6 & 35.77 & 17.14 & 10 & 22.14 & One type 4 and two type 1 \\
Delayed & 82.5 & 35.36 & 16.43 & 9.64 & 21.07 & One type 4 and four type 1 \\
\hline
\end{tabular}

* ROM, range of movement

$+A D L$, activities of daily living

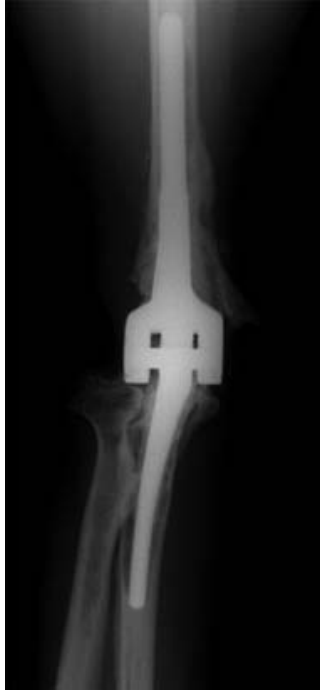

Fig. $2 a$

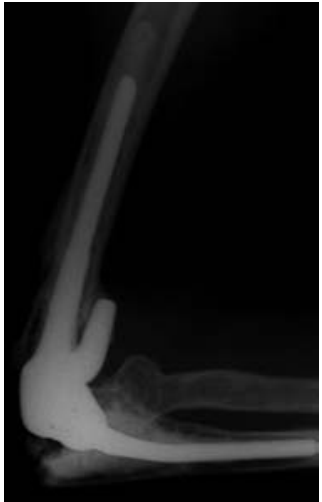

Fig. $2 b$
Type 4 loosening for both the humeral and ulnar components on a) anteroposterior and b) lateral radiographs of the same patient at 72 months follow-up.

(750 mg cefuroxine) are administered post-operatively. The drain is removed the day after surgery and active mobilisation begun as early as tolerated. Routine formal physiotherapy is not used.

Review and assessment. Clinical evaluation included measurement of elbow movement and assessment of the valgus/ varus stability of the elbow. The Mayo elbow performance score was used. It combines scores for pain, movement (flexion arc), stability and daily function, to produce a score out of 100. A score of 90 or above is deemed an excellent outcome, 75 to 89 good, 60 to 74 fair and less than 60 poor. All patients were asked whether they were satisfied with the procedure.

An assessment of pre-operative, immediately post-operative and latest radiographs was also performed. Anteroposterior (AP) and lateral radiographs at follow-up were compared with the immediate post-operative radiographs for evidence of loosening and implant failure. Loosening was graded between 0 and 4 as described by Morrey et al. ${ }^{12}$ Type 0 indicates a radiolucent line which is $<1 \mathrm{~mm}$ thick and involves $<50 \%$ of the interface; type 1 , a radiolucent line which is $1 \mathrm{~mm}$ thick and involves $<50 \%$ of the interface; type 2 , a radiolucent line which is $>1 \mathrm{~mm}$ thick and involves $>50 \%$ of the interface; type 3 , a radiolucent line which is $>2 \mathrm{~mm}$ thick and involves the whole interface; and type 4 , gross loosening.

Statistical analysis. The Mayo elbow performance scores of the early and delayed groups were compared using the MannWhitney U non-parametric test. Survivorship was analysed using the Kaplan-Meier method ${ }^{13}$ and the results were compared using a log-rank test. The complications were compared using a difference of proportions test. All statistical analyses were performed using StatSoft Inc. (2004), STATISTICA (data analysis software system, StatSoft Inc, Tulsa, Oklahoma), version 6.1. A p-value $<0.05$ was considered statistically significant.

\section{Results}

Clinical outcome. The mean follow-up for the whole group 32 patients (Table III) was 56.1 months (18 to 88). The minimum follow-up in patients who were alive was 24 


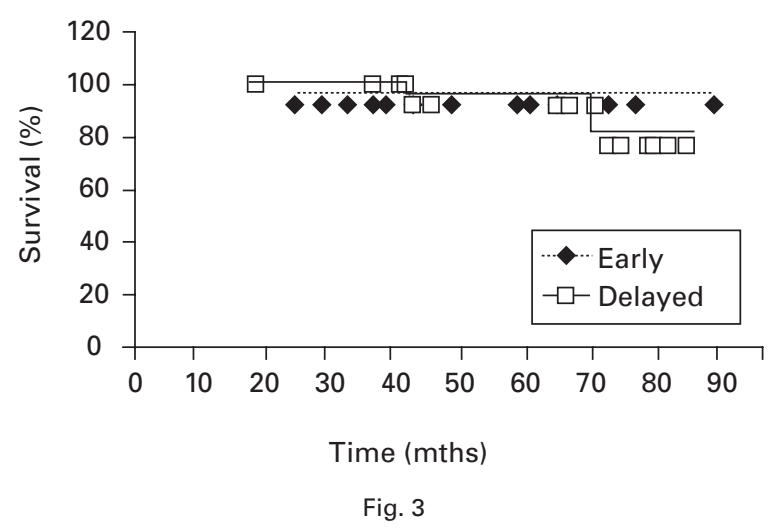

Kaplan-Meier survivorship analysis for early group and delayed group. The early total elbow replacement group has a survivorship of $93 \%$ at 88 months and the delayed total elbow replacement group has a survivorship of $76 \%$ at 84 months.

months and there was only one patient with a follow-up less than this (18 months) among the five patients who died. The median Mayo elbow performance score was 85 (55 to 100). The mean flexion was from $29^{\circ}\left(0^{\circ}\right.$ to $\left.70^{\circ}\right)$ to $120^{\circ}\left(90^{\circ}\right.$ to $\left.140^{\circ}\right)$. All elbows were stable on clinical examination.

In the subgroup of patients with an acute fracture (Table III) who had an early TER the mean follow-up was 52.4 months (24 to 88$)$. The mean flexion arc was from $26^{\circ}\left(0^{\circ}\right.$ to $\left.70^{\circ}\right)$ to $118.7^{\circ}\left(90^{\circ}\right.$ to $\left.140^{\circ}\right)$, forearm rotation was well preserved with pronation and supination of $70^{\circ}$ and $80^{\circ}$, respectively. There were eight patients with no pain, five with mild occasional pain and two with moderate pain. Two patients had mild restriction in daily activities. The outcome was excellent in five patients, good in six, and fair in two; two had died from unrelated causes. The fair outcomes were noted in a patient who had revision TER for aseptic loosening and in one patient who had post-injury, pre-surgery ulnar nerve damage which recovered incompletely and this patient developed a chronic regional pain syndrome.

The median Mayo elbow performance score was 85 (60 to 100$)$. On direct questioning 12 of the 13 patients $(92.3 \%)$ expressed satisfaction with the operation.

In the subgroup of patients who had a delayed TER (Table III), the mean follow-up was 57 months (18 to 84). The mean flexion arc was from $32^{\circ}\left(0^{\circ}\right.$ to $\left.70^{\circ}\right)$ to $120^{\circ}\left(95^{\circ}\right.$ to $140^{\circ}$ ), forearm rotation was again well preserved (70/ 70 pronation/supination) apart from one patient who had a complete block to supination. All elbows were stable. There were nine patients with no pain, six with mild pain and two with moderate pain. The outcome was excellent in six patients, good in five, fair in two and poor in one; three had died. The patient with a poor result had an ulnar nerve injury, chronic pain syndrome and infection, which eventually required removal of the implant at 42 months' follow-up. One of the patients with a fair result underwent a revision TER for aseptic loosening.

The median Mayo elbow performance score was 80 (55 to 100$)$. Of the 14 patients, 13 (92.9\%) expressed satisfaction.

Comparison of objective Mayo elbow performance score and subjective pain scores between the two groups of patients (Table IV) did not show any statistically significant difference using the Mann-Whitney U test $(\mathrm{p}=0.9$ and 0.55 , respectively). The subjective satisfaction rates in both the groups were similar.

Radiological outcome. The mean radiological follow-up for the whole group was 54 months (14 to 82) and the minimum radiological follow-up in patients who were alive was 24 months. The review of the latest radiographs showed that there was no radiolucent line in 23 elbows $(72 \%)$. These were classified as type 0 according to the Mayo classification system. There were four elbows with a type 1 ulnar lucency and two with a type 1 humeral lucency. Two had a type 4 lucency (Fig. 2) and both required revision. One had no implant as it was removed because of infection

Survivorship analysis. Kaplan-Meier survivorship analysis ${ }^{13}$ showed $84 \%$ survival at 88 months with revision or removal of the prosthesis as the end-point for the whole group of patients. Survivorship analysis for the early and delayed groups separately was $93 \%$ at 88 months and $76 \%$ at 84 months, respectively (Fig. 3). The comparison of these results did not show any statistical significance (log-rank test, $\mathrm{p}=0.66$ ).

Complications. The overall complication rate was seven of 32 patients $(21.9 \%)$. The number of complications in the early group was two of $15(13.3 \%)$ and five of $17(29.4 \%)$ in the delayed group. This did not show any statistical significance on comparison using the difference of proportions test $(\mathrm{p}=0.28)$.

There were no complications in 25 patients (78\%). One patient in the early group had pre-operative, post-injury ulnar nerve damage. There was partial recovery at final follow-up but the patient developed chronic regional pain syndrome. One patient with gross aseptic loosening in the early group underwent revision.

In the delayed group two patients had a post-operative ulnar nerve palsy, one of whom developed chronic regional pain syndrome and subseqently presented with a deep infection requiring removal of the implant. The ulnar neuropraxia in the second patient recovered completely at three months' follow-up. There was one case of mild heterotopic ossification and another patient had superficial infection. One further patient developed gross aseptic loosening requiring revision.

\section{Discussion}

Complex fractures of the distal humerus in the elderly remain a management challenge. Rigid osteosynthesis preserving the elbow and allowing early mobilisation remains 
the accepted mode of treatment in younger patients; however, adequate fixation of osteoporotic bone, especially small fragments, may not always be feasible. Several publications suggest that primary TER may be a valuable option in the primary management of these injuries. ${ }^{1-5}$

The single largest published series on Coonrad-Morrey TER for acute fractures of the distal humerus in the elderly is by Kamineni and Morrey. ${ }^{4}$ They reviewed 43 patients (29 alive at final review) with a mean age of 69 years and a mean follow-up of seven years. Assessment with the Mayo elbow performance score identified 40 elbows $(93 \%)$ with an excellent or good outcome. In this study 17 elbows had radiological changes secondary to RA and three OA. Garcia et $\mathrm{al}^{3}$ did not include patients with inflammatory or degenerative arthritis. They reviewed 19 patients (16 alive at final review) with a mean age of 73 years and a mean follow-up of three years. They also reported a $93 \%$ good to excellent result based on the Mayo elbow performance score.

In patients with nonunion of a supracondylar fracture an $88 \%$ satisfactory result was reported by Morrey and Adams ${ }^{7}$ in 1995 , but they also had a complication rate of $18 \%$. There is only one published study comparing the results of TER with osteosynthesis in elderly patients with fracture of the distal humerus. ${ }^{14}$ This was a retrospective study with 12 patients in each group. The TER group showed excellent or good results in 11 patients compared with eight in the osteosynthesis group.

Our study, however, involves the largest reported group of patients without inflammatory joint disease, from the United Kingdom, who underwent TER for fractures of the distal humerus with a mean follow-up of 56.1 months (18 to 88 ). We have also compared the outcome in patients who were treated acutely with those groups who underwent TER after a mean delay of more than one year. The results are slightly inferior to those from the Mayo clinic. ${ }^{4}$ In our study, the percentage of excellent or good results was approximately $84.6 \%$ in the acute fracture group and $78.5 \%$ in the delayed group. ${ }^{4}$ Of 17 patients in the delayed group, all had a painful nonunion of the distal humerus; 13 had undergone previous surgery which may have contributed to the inferior clinical results. The five patients who died had a mean follow-up of three years, the shortest follow-up being 18 months. There are other studies with satisfactory final results of over $90 \%$ based on the Mayo elbow performance score, but the overall follow-up period is less than that in our study. ${ }^{1,3}$ However, subjective assessment of both the groups has shown an encouraging satisfaction rate of $92 \%$.

We did not find any statistically significant difference in the functional outcome in patients undergoing delayed TER compared with those undergoing early TER. There was also no difference in the rate of complications.
The weaknesses of our study include its small sample size, the heterogeneity of the cases and variable intervals between injury and TER. Our attempt to make a meaningful comparison between two non-randomly selected groups of patients has not yielded statistically significant differences. Total elbow replacement for complex elbow trauma in the elderly is not a procedure which is routinely undertaken; even specialist elbow surgeons will perform relatively few such procedures.

In our series, almost $93 \%$ of the patients were satisfied with the result and $87.5 \%$ had no or only mild pain. The overall percentage of excellent or good results was $82 \%$. This study supports the conclusions made by other similar studies $^{1,3,4}$ that TER provides a predictable and reproducible result in terms of pain relief and function in elderly osteoporotic patients with difficult fractures of the distal humerus.

We would like to thank Dr C. Edwards, Consultant Medical Physicist, Royal Gwent Hospital Newport, for the statistical advice, Mr D. Doherty, Consultant Orthopaedic Surgeon, University Hospital of Wales, Cardiff for reviewing our paper, and Mrs H. Shewring, Medical Secretary, Llandough Hospital, Cardiff, for the excellent support work in the conduct of this study.

No benefits in any form have been received or will be received from a commercial party related directly or indirectly to the subject of this article.

\section{References}

1. Cobb TK, Morrey BF. Total elbow arthroplasty as primary treatment for distal humeral fractures in elderly patients. J Bone Joint Surg [Am] 1997;79-A:826-32.

2. Gambirasio R, Rians N, Stern R, Hoffmeyer P. Total elbow replacement for complex fractures of the distal humerus. J Bone Joint Surg [Br] 2001;83-B:974-8.

3. Garcia JA, Mykula R, Stanley D. Complex fractures of the distal humerus in the elderly: the role of total elbow replacement as primary treatment. J Bone Joint Surg [Br] 2002;84-B:812-16.

4. Kamineni S, Morrey BF. Distal humeral fractures treated with noncustom total elbow replacement. J Bone Joint Surg [Am] 2004;96-A:940-7.

5. Ray PS, Kakarlapudi K, Rajeskhar C, Bhamra MS. Total elbow arthroplasty as primary treatment for distal humeral fractures in elderly patients. Injury 2000;31:68792.

6. Figgie MP, Inglis AE, Mow CS, Figgie HE 3rd. Salvage of non-union of supracondylar fracture of the humerus by total elbow arthroplasty. J Bone Joint Surg [Am] 1989;71-A:1058-65

7. Morrey BF, Adams RA. Semiconstrained elbow replacement for distal humeral nonunion. J Bone Joint Surg [Br] 1995;77-B:67-72.

8. Landor I, Vavrik P, Jahoda D, Guttler K, Sosna A. . Total elbow replacement with the Souter-Strathclyde prosthesis in rheumatoid arthritis: long-term follow-up. J Bone Joint Surg [Br] 2006;88-B:1460-3.

9. Cesar M, Roussanne, Y Bonnel F, Canovas F. GSB III total elbow replacement in rheumatoid arthritis. J Bone Joint Surg [Br] 2007;89-B:330-4.

10. Morrey BF, An KN, Chao EYS. Functional evaluation of the elbow. In: Morrey BF, ed. The elbow and its disorders. Second ed. Philadelphia: WB Saunders, 1993:86-97.

11. Müller ME. The comprehensive classification of fractures of long bones. Berlin: Springer, 1990.

12. Morrey BF, Bryan RS, Dobyns H, Linscheid RL. Total elbow arthroplasty: a five year experience at Mayo clinic. J Bone Joint Surg [Am]1981;63-A:1050-63.

13. Kaplan EL, Meier P. Nonparametric estimation from incomplete observations. J Am Stat Assoc 1958:53:457-81

14. Frankle MA, Herscovici D Jr, DiPasquale TG, Vasey MB, Sanders RW. A comparison of open reduction and internal fixation and primary total elbow arthroplasty in the treatment of intraarticular distal humerus fractures in women older than age 65 . J Orthop Trauma 2003;17:473-80 